\title{
Infected foot ulcers in male and female diabetic patients: a clinico-bioinformative study
}

\author{
Shazi Shakil, Asad U Khan ${ }^{*}$
}

\begin{abstract}
Background: The study aimed at (i) characterizing the mode of transmission of bla $a_{\mathrm{CTX}-\mathrm{M}}$ and $b / a_{\mathrm{TEM}-1}$ among extended-spectrum- $\beta$-lactamase (ESBL)-producing Escherichia coli strains isolated from infected diabetic foot ulcers, and (ii) identifying the risk factors for "sex-associated multidrug resistant Gram-negative bacterial (MDRGNB)infection status" of the ulcers.

Methods: Seventy-seven diabetic patients having clinically infected foot ulcers were studied in a consecutive

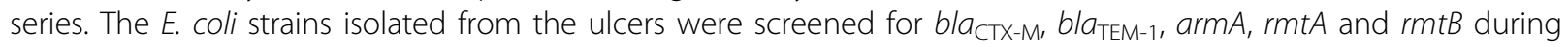
the 2-year study-period. PCR amplified bla $a_{C T X-M}$ genes were cloned and sequenced. Enterobacterial repetitive intergenic consensus (ERIC)-PCR was used for the analysis of genetic relatedness of the ESBL-producers. Risk factors for "sex-associated MDRGNB-infection status" of ulcers were assessed. Modeling was performed using Swiss-ModelServer and verified by Procheck and verify3D programmes. Discovery Studio2.0 (Accelrys) was used to prepare Ramachandran plots. Z-scores were calculated using 'WHAT IF'-package. Docking of cefotaxime with modeled CTXM-15 enzyme was performed using Hex5.1.

Results: Among 51 E. coli isolates, 14 (27.5\%) ESBL-producers were identified. Only 7 Class1 integrons, 2 bla $a_{\text {CTX-M-15, }}$ and 1 bla TEM $-1_{1}$ were detected. Ceftazidime and cefotaxime resistance markers were present on the plasmidic DNA of both the bla $a_{\mathrm{CTX}-\mathrm{M}-15}$ positive strains and were transmissible through conjugation. The residues Asn132, Glu166, Pro167, Val172, Lys234 and Thr235 of CTX-M-15 were found to make important contacts with cefotaxime in the docked-complex. Multivariate analysis proved 'Glycemic control at discharge' as the single independent risk factor.

Conclusions: Male diabetic patients with MDRGNB-infected foot ulcers have poor glycemic control and hence they might have higher mortality rates compared to their female counterparts. Plasmid-mediated conjugal transfer, albeit at a low frequency might be the possible mechanism of transfer of bla $a_{\mathrm{CTX}-\mathrm{M}-15}$ resistance marker in the present setting. Since the docking results proved that the amino acid residues Asn132, Glu166, Pro167, Val172, Lys 234 and Thr235 of CTX-M-15 (enzyme) make important contacts with cefotaxime (drug) in the 'enzyme-drug complex', researchers are expected to duly utilize this information for designing more potent and versatile CTX-Minhibitors.
\end{abstract}

\section{Background}

Multidrug resistant Gram-negative bacteria (MDRGNB) are a major therapeutic challenge both in hospital and community settings [1]. We have recently reported a high prevalence of extended-spectrum beta lactamase (ESBL)-producing bacteria in the neonatal intensive care unit of Aligarh hospital, India [2]. ESBLs are often plasmid-associated and there can be cross-species dissemination of these plasmids. Moreover, these plasmids

\footnotetext{
* Correspondence: asad.k@rediffmail.com

Interdisciplinary Biotechnology Unit, Aligarh Muslim University, Aligarh, India-
} 202002 often carry genes for co-resistance to other antibiotics such as aminoglycosides, fluoroquinolones, tetracyclines, chloramphenicol and sulfamethoxazole-trimethoprim. Concomitant $\beta$-lactam and aminoglycoside resistance involving arm $A$ and $r m t B$ genes is increasingly being reported [3].

Foot ulcers are a very common complication of type 1 and type 2 diabetes. The Indian diabetic population is expected to increase to 57 million by 2025 [4]. Individuals with diabetes have at least a 10 -fold greater risk of being hospitalized for soft tissue and bone infections of the foot than the individuals without diabetes [5].

\section{Biomed Central}


Infections of foot ulcers by ESBL-producing MDRGNB in diabetic patients have been described frequently [6]. Due to non-use of standard microbiological techniques, there is a paucity of ESBL data concerning diabetic foot ulcers particularly in India.

CTX-Ms have become the most prevalent ESBLs worldwide. It is of due importance to know the amino acid residues crucial to the interaction between cefotaxime and CTX-M-15, as this enzyme is increasingly being reported from this part of the world together with TEM-1 [7]. Moreover, Escherichea coli is one of the most common infecting organisms isolated from soft tissue infections [8]. Accordingly we looked for the mode of transmission of $b l a_{\mathrm{CTX}-\mathrm{M}}$ and $b l a_{\mathrm{TEM}-1}$ resistance markers among the E. coli strains isolated from infected foot ulcers of diabetic patients admitted to the endocrinology ward of the Aligarh hospital. The study aimed at (i) characterizing the mode of transmission of $b l a_{\mathrm{CTX}-\mathrm{M}}$ and $b l a_{\mathrm{TEM}-1}$ among ESBL-producing $E$. coli strains isolated from infected diabetic foot ulcers, and (ii) identifying the risk factors for "sex-associated MDRGNB infection status" of the ulcers.

\section{Methods}

\section{Collection of bacterial strains and patients' details}

The study was conducted at Aligarh hospital, India (from April 2007 to November 2008). Seventy-seven diabetic patients having clinically infected foot ulcers admitted to the endocrinology ward were studied in a consecutive series. Wagner classification was employed to grade the ulcers [9]. Thirty-two study factors were recorded for each patient. BMI i.e. Body Mass Index $(<$ $18.5 \mathrm{~kg} / \mathrm{m}^{2}=$ underweight; $18.5-22.9 \mathrm{~kg} / \mathrm{m}^{2}=$ normal weight; $23.0-24.9 \mathrm{~kg} / \mathrm{m}^{2}=$ overweight), presence of nephropathy (creatinine $\geq 150 \mu \mathrm{mol} / \mathrm{l}$ or presence of micro- or macroalbuminuria), neuropathy (absence of perception of the Semmes-Weinstein monofilament at 2 of 10 standardized plantar sites on either foot) and peripheral vascular disease (ischemic symptoms and intermittent claudication or rest pain, with or without absence of pedal pulses), were some of them. Osteomyelitis was diagnosed on suggestive changes in the radiographs and bone scans. Regarding a fasting blood glucose level of $<110 \mathrm{mg} / \mathrm{dl}$ and/or postprandial level of $<160 \mathrm{mg} / \mathrm{dl}$ as glycemic control, the number of patients achieving glycemic control over the hospital stay was compared with respect to sex. In case a patient had multiple ulcers, specimens from all the ulcers were taken. If any of the ulcers was found to be infected with MDRGNB, the patient was grouped in the MDRGNBinfected category. Fasting HDL and VLDL were measured and LDL was calculated by subtracting their sum from total cholesterol. Clinical assessment for signs of infection (swelling, exudate, surrounding cellulitis, odor, tissue necrosis, crepitation, and pyrexia) was made. Ulcer size was determined by multiplying the longest and widest diameters and expressed in centimeters squared. Demographic and other relevant details were retrieved from medical records.

\section{Microbiological methods}

Culture specimens were obtained at the time of admission, after the surface of the wound had been washed vigorously by saline, and followed by debridement of superficial exudates. Specimens were obtained by scraping the ulcer base or the deep portion of the wound edge with a sterile curette. The soft tissue specimens were quickly sent to the laboratory and processed for Gram-negative bacteria. Standard methods for isolation and identification of bacteria were used [10]. Antimicrobial susceptibility testing of the isolates was performed by the standard disc diffusion method as recommended by the Clinical and Laboratory Standards Institute (CLSI) [11]. The test-antibiotics included gentamycin, tobramycin, amikacin, kanamycin, streptomycin, cefalothin, cefazolin, cefuroxime, cefoxitin, ceftazidime, cefotaxime, ceftriaxone, cefepime, ciprofloxacin, norfloxacin, tetracycline, piperacillin, imipenem as well as combinations such as amoxyclav and piperacillin/tazobactam. Minimum Inhibitory Concentrations (MICs) for the same antimicrobials were determined by the CLSI microbroth dilution method [11]. The ESBL synergy test for the study isolates was performed as described by Jarlier et al [12]. For this study, bacteria resistant to at least 4 of the test antibiotics were designated as MDRGNB. All ESBL-producers were considered as MDRGNB.

\section{Molecular typing and PCR}

Enterobacterial repetitive intergenic consensus (ERIC)PCR was used for the analysis of genetic relatedness of the ESBL-producers as described elsewhere [13]. A search for bla $a_{\mathrm{CTX}-\mathrm{M}}, b l a_{\mathrm{TEM}-1}, a r m A, r m t A$ and $r m t B$ genes in the genomic and plasmidic DNA of isolates which were positive for ESBL synergy test was performed by PCR amplification, as described previously [14-16]. Plasmids were obtained by the method of Kado and Liu [17]. Screening of integrons was also performed as described elsewhere [18].

\section{Cloning and sequencing}

PCR amplified $b l a_{\text {CTХ-м }}$ genes, were ligated into 'pDrive-easy-PCR-cloning-vector' and transformed into competent E. coli $\mathrm{C} 600$ cells using Qiagen Cloningplus Kit (Qiagen, USA). Transformed colonies were selected on Luria-Bertani agar plates, containing isopropyl- $\beta-D-$ thiogalactopyranoside $(1 \mathrm{mM})$, 5-bromo-4-chloro-3indolyl- $\beta$-D-thiogalactopyranoside $(40 \mathrm{mg} / \mathrm{L})$ and kanamycin $(30 \mathrm{mg} / \mathrm{L})$. Plasmid extracted from the culture of a well-isolated white colony was used as template for PCR amplifications of $b l a_{\mathrm{CTX}-\mathrm{M}}$. The same plasmids 
were transformed [19] into azide-resistant E. coli J53 cells. The transformants were selected on Luria-Bertani agar plates containing azide $(250 \mathrm{mg} / \mathrm{L})$, cefotaxime $(2$ $\mathrm{mg} / \mathrm{L})$ and kanamycin $(30 \mathrm{mg} / \mathrm{L})$. The transformed cells were re-checked for ESBL-production. DNA sequences were analyzed with ABI 3130 Genetic Analyzer (Applied Biosystems). The Basic Local Alignment Search Tool (BLAST) program of the National Center for Biotechnology Information http://www.ncbi.nlm.nih.gov was used to search databases for similar nucleotide sequences.

\section{Marker transfer experiments}

E. coli strains that were PCR-positive for any of the tested genes were used as donors in transconjugation experiments as described elsewhere [20]. Azide-resistant E. coli $\mathrm{J} 53$ was used as the recipient. Transconjugants were selected on Luria-Bertani agar plates containing azide $(250 \mathrm{mg} / \mathrm{L})$ and either cefotaxime $(2 \mathrm{mg} / \mathrm{L})$ or gentamicin $(50 \mathrm{mg} / \mathrm{L})$.

\section{Statistical analysis}

Qualitative variables were expressed as percentages and quantitative variables were expressed as means \pm SD (Standard Deviation). Significance of the study variables for "sex-associated MDRGNB infection status" of the foot ulcers was tested by using Student's $t$ test or Fisher's exact test as appropriate. All risk factors that proved to be statistically significant on univariate analysis were entered by blockwise entry in a logistic regression model after exclusion of multicollinearity and interaction between variables. A two-tailed $p$ value of $<0.05$ was taken as significant. Statistical analysis was performed using SPSS (version 11.5, Chicago). The results were again confirmed using the SISA (Simple Interactive Statistical Analysis) program http://www.quantitativeskills.com/sisa/distributions/binomial.htm

\section{Homology Modeling and Docking}

BLAST-P was performed to retrieve suitable templates for homology-modeling using the $b l a_{\mathrm{CTX}-\mathrm{M}}$ sequences obtained in this study. Protein Data Bank (PDB) IDs of these templates are shown in table 1 . Models were prepared using Swiss-Model-Server [21] and verified by Procheck [22] and verify3D programmes [23]. Discovery Studio2.0 (Accelrys) was used to prepare Ramachandran plots. Z-scores were calculated using 'WHAT IF'-package. Cefotaxime was docked into each of the modeled structures employing Hex 5.1.

\section{Results}

\section{General results}

A total of 185 Gram-negative bacteria were isolated from 95 foot ulcer samples of the 77 diabetic patients admitted during the study-period. Out of these bacteria, 149 (80.5\%) were found to be MDRGNB. Sixty-six samples which belonged to 55 patients were found to harbor
Table 1 Analysis of bla $a_{\mathrm{CTX}-\mathrm{M}-15}$ markers using bioinformatic approach and clinical profile

\begin{tabular}{lcc}
\hline CTX-M-15 positive E. coli strain & D253 & D281 \\
\hline ERIC profile & M1 & M1 \\
\hline Class1 integron & + & + \\
\hline int1 & + & + \\
\hline sul1 & + & + \\
\hline Sampling date & $8 / 4 / 2008$ & $14 / 6 / 2008$ \\
\hline Sex of the patient & Female & Male \\
\hline $\begin{array}{l}\text { Accession no. of reference strain used } \\
\text { for alignments }\end{array}$ & FJ668785 & FJ668753 \\
\hline $\begin{array}{l}\text { "PDB ID of the template retrieved for } \\
\text { modeling }\end{array}$ & 1 iiysA & 1 iysA \\
\hline Cefotaxime MIC of the strain (mg/L) & 256 & 64 \\
\hline Ceftazidime MIC of the strain (mg/L) & 32 & 32 \\
\hline${ }^{* E-t o t a l ~(K j / m o l) ~}$ & -221.51 & -168.17 \\
\hline *E-shape (Kj/mol) & -208 & -147.5 \\
\hline *E-force (Kj/mol) & -13.51 & -20.67 \\
\hline $\begin{array}{l}\text { Genbank accession numbers (This } \\
\text { study) }\end{array}$ & FJ997866 & GQ145220 \\
\hline
\end{tabular}

"PDB = Protein Data Bank

${ }^{*} \mathrm{E}=$ Binding energy with cefotaxime

these MDRGNB. Fig 1 shows the distribution of MDRGNB obtained from infected diabetic foot ulcers divided into 2-month periods from April 2007 to November 2008. Characteristics of male and female patients having MDRGNB-infected foot ulcers were recorded. Among the 55 MDRGNB-infected patients, 46 (83.6\%) were males while $9(16.4 \%)$ were females. Grade-5 ulcer was found in 1 male patient only. The majority of subjects $(89.1 \%)$ had type 2 diabetes. Fiftyone $(92.7 \%)$ were hypertensive, $22(40 \%)$ had retinopathy, 37 (67.3\%) had nephropathy, 34 (61.8\%) had neuropathy and $33(60 \%)$ had peripheral vascular disease. Nine $(16.4 \%)$ patients had osteomyelitis. Three male patients died during the hospital stay. However, there were only 2 subjects who possessed foot ulcer infected with more than 1 ESBL-producing strain.

\section{Antimicrobial susceptibility and ESBL-production}

Forty-three (28.9\%) ESBL-producers were identified among the 149 MDRGNB. The highest ESBL production was noted in Pseudomonas aeruginosa (20/61; $32.8 \%)$, followed by E. coli $(14 / 51 ; 27.5 \%)$ and K. pneumoniae (9/38; 23.7\%). All the MDRGNB showed 100\% susceptibility to imipenem (data not shown). All the ESBL-producers, with the exception of $P$. aeruginosa strains were found to be susceptible to cefoxitin, imipenem and piperacillin/tazobactam while the same were resistant to ceftazidime, cefotaxime and piperacillin. However, the ESBL producing strains of $P$. aeruginosa were invariably resistant to cefoxitin. Amikacin was the most effective of all the aminoglycosides against ESBLproducers. Imipenem alone and the piperacillin/ 


\section{Figure 1}

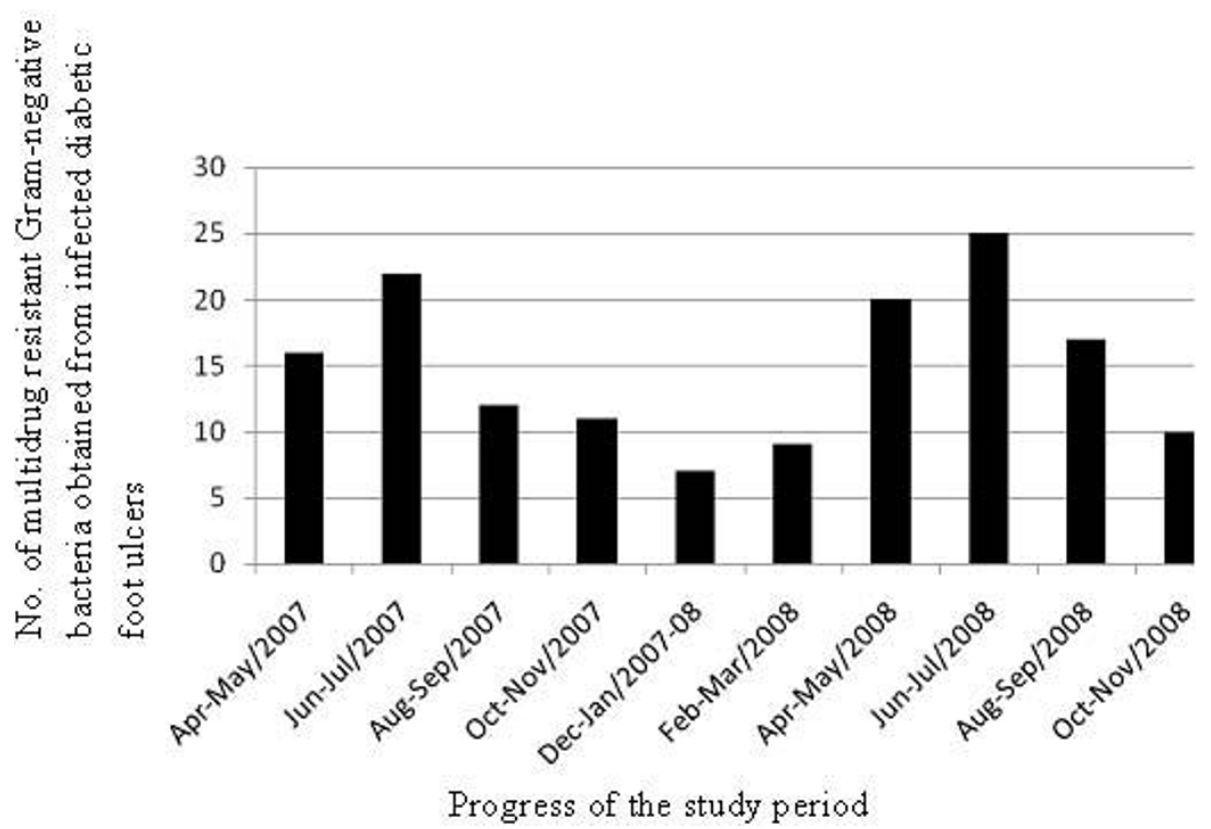

Figure 1 Distribution of multidrug resistant Gram-negative bacteria obtained from infected diabetic foot ulcers divided into 2-month periods from April 2007 to November 2008.

tazobactam combination were found to be the therapies of choice. Hence, the 43 ESBL-producers could be broadly divided into 3 different resistance patterns. Strains resistant to aminoglycosides and quinolones but susceptible to cefepime constituted pattern 1. Pattern 2 comprised of strains resistant to cefepime but susceptible to either aminoglycosides or quinolones or both. Strains resistant to all the three mentioned classes of antibiotics constituted pattern 3. Resistance pattern 1 was found to be the most common among ESBL-producers. The other aerobic Gram-negative organisms isolated from foot ulcers included Acinetobacter baumannii (5 strains), Proteus species (20 strains), Enterobacter species (1 strain) and Morganella morganii (1 strain). None of these were ESBL-producers. Only 13 anaerobes were isolated of which 8 were Gram-negative. The Gram-negative anaerobes consisted of Veillonella species (3 strains) and Bacteroides species (5 strains) none of which happened to be MDRGNB.

PCR amplifications, cloning and sequencing of bla ${ }_{C T X-M-15}$ Only 2 strains were confirmed to harbor $b l a_{\text {СтХ-M }}$ by PCR. Strain D253 was positive for both $b l a_{\text {СTX-M }}$ and $b l a_{\text {TEM-1 }}$ while strain D281 possessed only $b l a_{\text {CTX-M. }}$. None of the strains were positive for any of the $16 \mathrm{~S}$ rRNA methyl transferase genes (i.e. $\operatorname{armA}, \operatorname{rmtA}$ or $r m t B)$. Seven integrons were detected whose sizes ranged from $600 \mathrm{bp}$ to $1.5 \mathrm{~Kb}$. All these integrons were found to be Class1 type and were positive for int1 and sul1 genes of the expected sizes $845 \mathrm{bp}$ and $840 \mathrm{bp}$ respectively. None of the genes were located in the integrons. E. coli C600 cells harboring cloned bla $a_{\text {СТХ-M }}\left(\right.$ C600 ${ }^{\text {bla CTX-M }}$ ) were again found to be PCR-positive for the said gene in all instances. Moreover, cultures derived from C600 blaCTX-M cells gave a positive ESBL synergy test. Azide resistant $E$. coli $\mathrm{J} 53$ cells transformed with the plasmidic DNA extracted from C600 blaCTX-M cells became cefotaxime resistant. Also, cultures derived from these transformed E. coli J53 cells were found to be positive for the ESBL test. Sequencing results confirmed all the $b l a_{\mathrm{CTX}-\mathrm{M}}$ genes obtained in this study as $b l a_{\mathrm{CTX}-\mathrm{M}-15}$.

Plasmid mediated marker transfer and molecular typing

The ceftazidime and cefotaxime resistance markers were located on the plasmidic DNA of both the $b l a_{\mathrm{CTX}-\mathrm{M}-15}$ positive strains and were transmissible through conjugation. Quinolone (ciprofloxacin) resistance was co-transferred with cefotaxime resistance, in only one of the $b l a_{\text {CTX-M-15 }}$ positive isolates. Transfer frequencies (Total no. of transconjugants per plate/Total no. of recepients per plate) observed were of the order $10^{-5}$ (Table 2). Randomly taking a single representative strain in case of identical susceptibility patterns, ERIC-PCR was performed for 40 ESBL-producers. P. aeruginosa, K. pneumoniae and E. coli displayed 5, 5 and 8 major ERICprofiles respectively (Fig 2 ). Both the $b l a_{\text {CTX-M-15 }}$ positive strains were found to be clonally related and displayed ERIC-profile M1 (Table 1). 
Table 2 Transconjugation frequencies, resistance markers transferred to recipient strains and MICs of antibiotics used against bla $a_{\mathrm{CTX}-\mathrm{M}-15}$ positive strains of $E$. coli

\begin{tabular}{|c|c|c|}
\hline Name of the strain & D253 & D281 \\
\hline MIC (mg/L) & 0 & 0 \\
\hline Gentamicin (G) & 128 & 64 \\
\hline Tobramycin (Tb) & 64 & 32 \\
\hline Kanamycin (Ka) & 64 & 128 \\
\hline Amikacin (Ak) & 32 & 32 \\
\hline Streptomycin (St) & 64 & 64 \\
\hline Cefazolin (Cz) & $>256$ & $>256$ \\
\hline Ceftazidime (Ca) & 32 & 32 \\
\hline Cefotaxime $(\mathrm{Ce})$ & 256 & 64 \\
\hline Ceftriaxone (Ci) & 256 & 512 \\
\hline Cefepime (Cpm) & 64 & 64 \\
\hline Ciprofloxacin (Cf) & 64 & 64 \\
\hline Norfloxacin (Nx) & 64 & 32 \\
\hline Piperacillin (Pc) & $>256$ & 512 \\
\hline Amoxyclav (Ac) & 4 & 2 \\
\hline Tetracycline $(\mathrm{T})$ & 256 & 512 \\
\hline $\begin{array}{l}\text { Resistance pattern } \\
\text { type }\end{array}$ & 3 & 3 \\
\hline $\begin{array}{l}\text { Resistance markers } \\
\text { present in donor or } \\
\text { test isolates }\end{array}$ & $\begin{array}{l}\mathrm{G}, \mathrm{Tb}, \mathrm{Ka}, \mathrm{St}, \mathrm{Ch}, \mathrm{Cz}, \\
\mathrm{Cu}, \mathrm{Ca}, \mathrm{T}, \mathrm{Ce}, \mathrm{Ci}, \mathrm{Cpm}, \\
\mathrm{Cf}, \mathrm{Nx}, \mathrm{Pc}\end{array}$ & $\begin{array}{l}\mathrm{G}, \mathrm{Tb}, \mathrm{Ka}, \mathrm{St}, \mathrm{Ch}, \mathrm{Cz}, \\
\mathrm{Cu}, \mathrm{Ca}, \mathrm{T}, \mathrm{Ce}, \mathrm{Ci}, \mathrm{Cpm} \text {, } \\
\mathrm{Cf}, \mathrm{Nx}, \mathrm{PC}\end{array}$ \\
\hline $\begin{array}{l}\text { Resistance markers } \\
\text { transferred to the } \\
\text { recipient }(E . \text { colij53) }\end{array}$ & $\mathrm{Ca}, \mathrm{Ce}, \mathrm{Ci}, \mathrm{T}$ & $\mathrm{Ca}, \mathrm{Ce}, \mathrm{Ci}, \mathrm{Cf}$ \\
\hline $\begin{array}{l}\text { Total no. of } \\
\text { transconjugants per } \\
\text { plate }\end{array}$ & $1.7 \times 10^{2}$ & $2.1 \times 10^{2}$ \\
\hline $\begin{array}{l}\text { Total no. of recepients } \\
\text { (E. coliJ53) per plate }\end{array}$ & $10^{7}$ & $10^{7}$ \\
\hline $\begin{array}{l}\text { Tansfer Frequency } \\
\text { (Total No. of } \\
\text { transconjugants per } \\
\text { plate/Total no. of } \\
\text { recepients per plate) }\end{array}$ & $1.7 \times 10^{-5}$ & $2.1 \times 10^{-5}$ \\
\hline
\end{tabular}

\section{Homology modeling and docking}

Over $90 \%$ of the amino acid residues in the protein structures modeled from $b l a_{\mathrm{CTX}-\mathrm{M}-15}$ genes obtained in this study were found to be present in the most favorable regions as revealed by their respective Ramachandran plots. The Ramachandran Z-score for modeled enzyme from strain D253 was found to be 0.027 (Fig $3 a)$, which further confirms the accuracy of the modeled structure. Cefotaxime was docked into the modeled enzyme-structures. It was found that the strain (D253) having a higher cefotaxime MIC displayed a higher negative binding energy as well (Table 1). Analysis of the docked structures by Discovery Studio2.0 revealed that the amino acid residues Asn132, Glu166, Pro167, Val172, Lys234 and Thr235 make important contacts with cefotaxime (Fig 3b).

\section{Risk factor analysis}

In the univariate analysis, many study variables including mean age, mean ulcer duration, smoking, Wagner grade and 'glycemic control at discharge' (all p $=0.00$ ) were found to be significant for "sex-associated MDRGNB infection status" of the foot ulcers. Hence, we went for multivariate analysis. The multiple logistic regression model confirmed 'glycemic control at discharge' to be the single independent risk factor for the same. $(p=0.001)$. ORs and $95 \%$ CIs can be seen in Additional file 1. Hence our main finding is that, male diabetic patients having MDRGNB-infected foot ulcers have poor glycemic control during the hospital stay.

\section{Nucleotide sequence accession numbers}

The accession numbers of the $E$. coli genes sequenced in this study are [GenBank: FJ997866], [GenBank: FJ997867] and [GenBank: GQ145220].

\section{Discussion}

This is the first study to report on risk factors for "sexassociated MDRGNB-infection status" of diabetic foot ulcers from this region of India (Uttar Pradesh). We do not claim that these 77 patients represent the entire region. Hence, similar studies from this region and across the globe that could help in updating the empirical antibiotic regimen in diabetic foot ulcers are highly recommended. We regret that we could not use bone biopsy sample in case of osteomyelitis. Bone biopsy may be traumatic to patient and is not routinely performed in our hospital. Moreover, Pellizzer et al. [24] have reported that samples taken from the base of the wound after debridgement are adequate to identify the infecting organism, which we needed. Infections due to multidrug resistant organisms in hospitalized patients with diabetic foot ulcers have been reported previously [25]. Compared with earlier reports, we recovered fewer anaerobic species [26]. Our patients did not have chronic draining wounds, and very few had gangrene associated with their infections. This may be an indication of fewer anaerobic species among nonthreatening lower-extremity infections, which has been reported earlier [27]. Patients with diabetic foot ulcers whose blood glucose levels are poorly controlled exhibit higher mortality rates [28]. Our results indicate that male diabetic patients with MDRGNB-infected foot ulcers have poor glycemic control. Hence, male diabetic patients having MDRGNB-infected foot ulcers might have higher mortality than their female counterparts. Studies have reported 'male sex' as a significant risk factor for nonhealing foot ulcers [29]. In a study by Basit et al. [30] hypertension was found to be significantly associated with poor glycemic control $(\mathrm{OR}=1.65)$. Also, in a study by Minh et al. [31], the prevalence of hypertension was found to be significantly higher among men than 


\section{Figure 2}

(a) P. aeruginosa (19 strains)

M A1B C1C2B C1C1C3B C3 C4D D B D E E D E

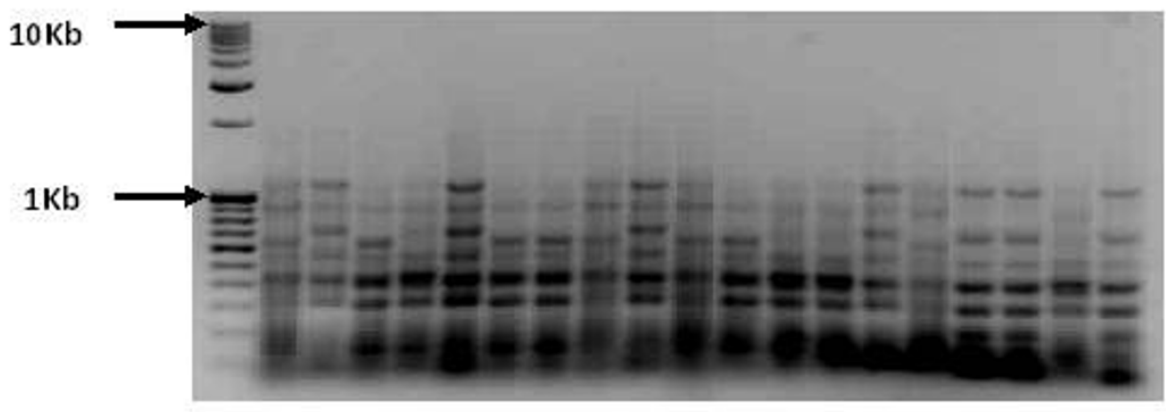

(b) K. pneumoniae ( 7 strains)

\section{F G H I I J1 J2}

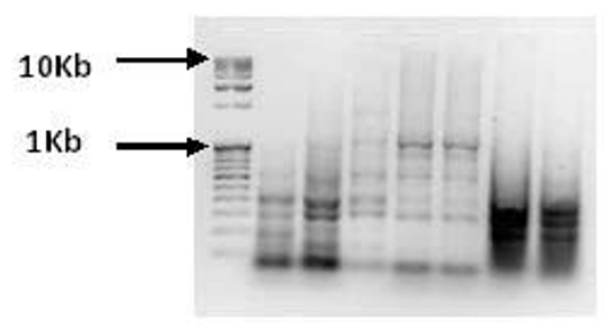

(c) E. coli (14 strains)

\section{MK1 K2 L M1M1K3M2 N O M1 P QR1R2}

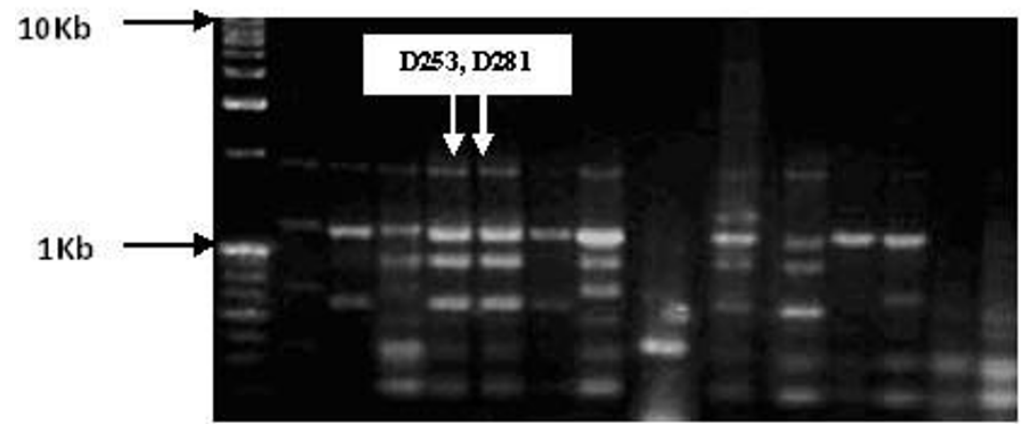

Figure 2 ERIC-profiles of extended-spectrum $\beta$-lactamase producing bacteria isolated from infected foot ulcers of diabetic patients. ' $M$ ' stands for marker (the first lane of each figure).

women. Accordingly in our study, taking the absence of hypertension as a baseline $(\mathrm{OR}=1.00)$, presence of hypertension with a presence of 'glycemic control at discharge' showed an OR of 0.375 while the same with an absence of 'glycemic control at discharge' showed an OR of 18.0. Hence, an absence of glycemic control with the presence of hypertension appears to be a strong indicator of MDRGNB-infections in male diabetic patients.
A surveillance program reported the frequency of ESBL-producing K. pneumoniae to be approximately 37\% in Latin America vs. $7 \%$ in the United States [32]. Plasmid mediated $b l a_{\mathrm{CTX}-\mathrm{M}-15}$ among clinical isolates have also been reported earlier [33]. Only 2 of our 43 ESBL-producing strains were PCR-positive for $b l a_{\mathrm{CTX}-\mathrm{M}-}$ 15. This is in harmony with a study in which the authors detected only 3 strains out of 365 clinical isolates that were PCR-positive for $b l a_{\mathrm{CTX}-\mathrm{M}-15}$ [34]. However, this 

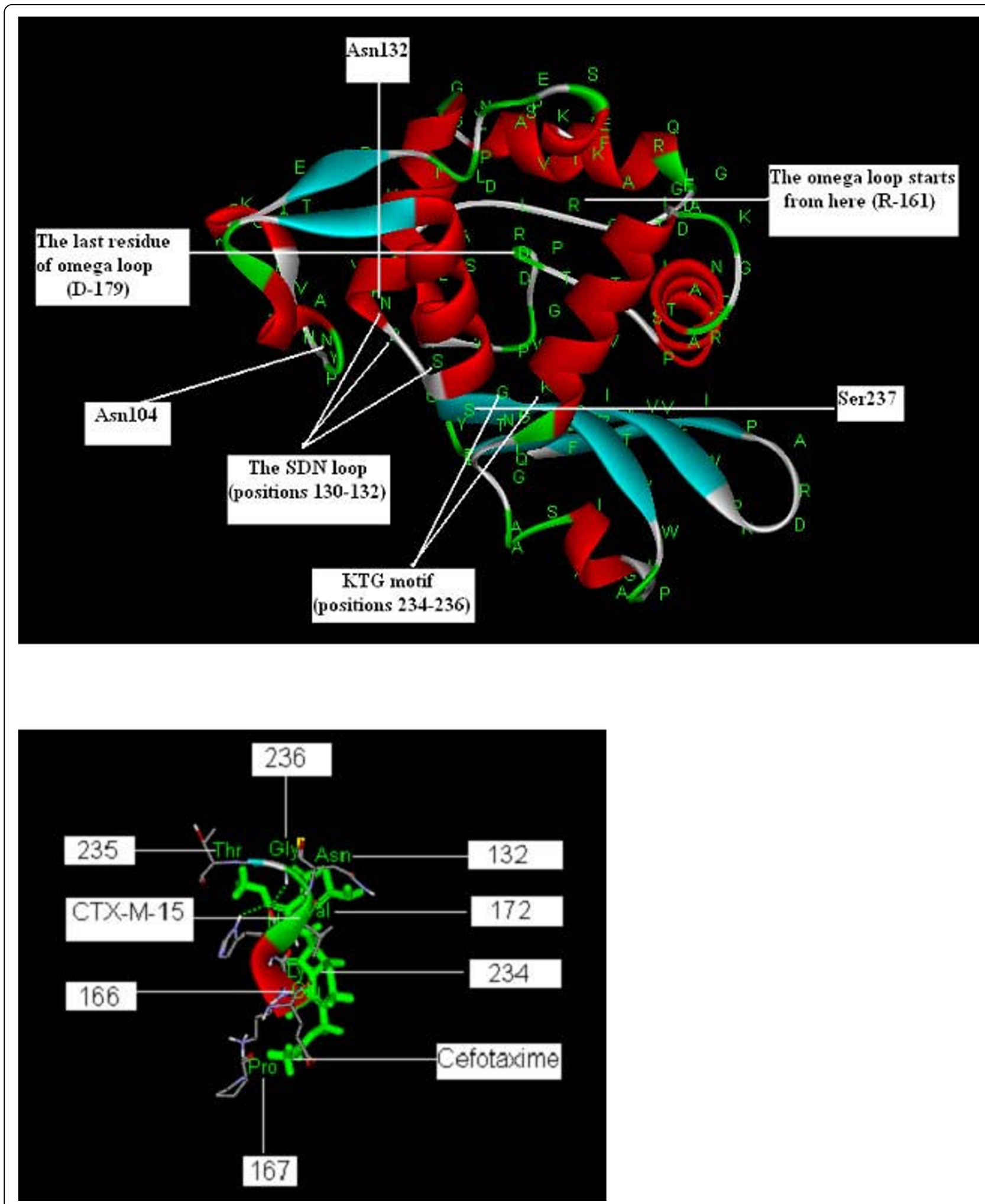

Figure 3 (a) CTX-M-15 enzyme modeled from the bla $a_{\mathrm{CTX}-\mathrm{M}-15}$ gene sequence [Genbank: FJ997866] of $E$. coli strain D253. The active site $\Omega$-loop, the SDN loop and the KTG motif are labeled. $A=91.5 \%, B=7.8 \%, C=0.7 \%, D=0.0 \%$, where ' $A$ ', ' $B$ ', 'C' and 'D' stand for percent amino acid residues in most favored, additional allowed, generously allowed and disallowed regions of the Ramachandran plot respectively. The $\mathrm{z}$-score for the modeled structure was equal to 0.027. (b) Amino acid residues crucial to the interaction between cefotaxime and CTX-M-15. 
observation was contrary to many findings, which have reported a high prevalence of bla $a_{\mathrm{CTX}-\mathrm{M}-15}$ among clinical isolates [35]. ESBL-production in the remaining ESBLpositive strains might be due to ESBL-types other than CTX-Ms such as SHV/OXA/TEM/GES/BES/PER/TLA/ IBC etc. as each of these have many variants. A high prevalence of ESBL-producers was observed in strains of $P$. aeruginosa (32.8\%), which is generally considered to be a rare ESBL-producer. This result was in harmony with the reports from Peshawar, Pakistan (close to North India) and even Delhi (India) which is adjacent to Aligarh. The authors of these studies have reported $35.85 \%$ and $33.6 \%$ ESBL-producers among $P$. aeruginosa isolates, respectively [36,37]. However, since the sample sizes were not large, we prefer to conclude that the observations regarding high prevalence of ESBL-producers among $P$. aeruginosa strains made in these studies as well as ours might have been simply matters of coincidence. Class 1 integrons are the most commonly found integron type in Gram-negative bacteria [38]. Accordingly, we detected 7 class1 integrons all of which were invariably PCR-positive for int1 and sul1. None of the bla $a_{\mathrm{CTX}-\mathrm{M}-15}$ markers were found to be located within the integrons. Hence, it is confirmed that the horizontal transfer of these markers was not integron-mediated but whole plasmid-mediated in our setting. Authors have earlier reported whole plasmid-mediated transfer of $b l a_{\mathrm{CTX}-\mathrm{M}-15}$ despite the presence of integron [39]. Transconjugation experiments were successful in case of both the $b l a_{\mathrm{CTX}-\mathrm{M}-15}$ positive $E$. coli strains in the present study. It is important to mention here that in medical literature, not all transfer experiments were successful with ESBL-producing E. coli. In a study, 19 of 24 strains did not transfer the ESBLs [40]. Similarly only $38 \%$ success was attained in transfer of markers by conjugation in another study [41]. The presence of strains co-resistant to aminoglycosides, quinolones and third generation cephalosporins as observed in our setting is a matter of due concern. Such strains if combined with the production of carbapenemase might result in therapeutic dead-ends [42,43].

This is the first study to report modeling of CTX-M-15 enzyme which is one of the most common ESBLs in India and its docking with cefotaxime. Moreover, there is no entry for CTX-M-15 in the Protein Data Bank to date. Residues specifically in the active site omega loop (position 161-179) of CTX-M enzymes play an important role in the substrate profile for cephalosporins [44]. But residues outside the omega loop might also help in fixing cefotaxime into the active site of the enzyme, such as Asn-132 [45]. Accordingly we found that the residues Asn132, Glu166, Pro167, Val172, Lys234 and Thr235 make important contacts with cefotaxime in the docked complex. The SDN (positions 130-132), and KTG (positions 234-236) sequences, were found to be conserved, which are typical structure of class A enzymes [46]. The sequences harbored the D240G mutation with respect to CTX-M-3, the distinguishing feature of CTX-M-15 enzymes. None of the mutations obtained in our CTX-M-15 sequences lied within the omega loop or other positions that are known to affect catalytic properties or substrate profile of these enzymes. Hence the MIC values for cefotaxime and ceftazidime antibiotics in these isolates were typical of CTXM-15 producers (Table 2). The bla $a_{\mathrm{CTX}-\mathrm{M}-15}$ positive isolates displayed cefotaxime MICs up to 8 fold higher than ceftazidime MICs. The strain having a higher cefotaxime MIC displayed a higher negative binding energy as well (Table 1). It can be explained by the fact that a higher negative value of binding energy for the enzyme-antibiotic complex is an indicator of more stable and effective binding. A more stable and better fitting of the $\beta$-lactam antibiotic (cefotaxime) into the active site of the CTX-M-15 enzyme would ensure an easy hydrolysis of the drug. This is in coherence with one of our earlier observations in which we performed docking of the enzyme Sme1 with different carbapenems to compare their effectiveness against Sme1 producing bacteria [47]. It was observed that the imipenem-Sme1 complex was far more stable than the complex involving doripenem, the overall most effective carbapenem to date. This suggested an easier hydrolysis of imipenem by Sme-1 and a poor hydrolysis of doripenem.

\section{Conclusions}

The following conclusions can be drawn from this study: (i) Male diabetic patients with MDRGNB-infected foot ulcers have poor glycemic control and hence they might have higher mortality rates compared to their female counterparts (ii) Plasmid-mediated conjugal transfer, albeit at a low frequency might be the possible mechanism of transfer of bla $a_{\mathrm{CTX}-\mathrm{M}-15}$ resistance marker in the present setting. (iii) Since the docking results proved that the amino acid residues Asn132, Glu166, Pro167, Val172, Lys234 and Thr235 of CTX-M-15 (enzyme) make important contacts with cefotaxime (drug) in the 'enzyme-drug complex', researchers are expected to duly utilize this information for designing more potent and versatile CTX-M-inhibitors.

\section{Acknowledgements}

This study was supported by internal funds of Biotechnology Unit, Aligarh Muslim University, Aligarh, India. SS thanks the Department of Biotechnology (DBT), Govt. of India for his research fellowship. We thank all of the staff and clinicians of the Aligarh hospital who participated in the study for their support and participation.

\section{Authors' contributions}

SS has performed all the experiments incorporated in this manuscript. AUK has designed the problem, approved the final draft of the manuscript and was a guide throughout this study. 


\section{Competing interests}

The authors declare that they have no competing interests.

Received: 9 October 2009

Accepted: 14 January 2010 Published: 14 January 2010

\section{References}

1. Shakil S, Khan R, Zarrilli R, Khan AU: Aminoglycosides versus bacteria-a description of the action, resistance mechanism, and nosocomial battleground. J Biomed Sci 2008, 15:5-14.

2. Shakil S, Ali SZ, Akram M, Khan AU: Risk factors for extended-spectrum $\beta$ lactamase producing Escherichia coli and Klebsiella pneumoniae acquisition in a neonatal intensive care unit. J Trop Pediatr 2009, doi:10.1093/tropej/fmp060.

3. Ma L, Lin CJ, Chen JH, et al: Widespread Dissemination of Aminoglycoside Resistance Genes armA and $r m t B$ in Klebsiella pneumoniae Isolates in Taiwan Producing CTX-M-Type ExtendedSpectrum $\beta$-Lactamases. Antimicrob Agents Chemother 2009, 53:104-111.

4. Abdul $H$, Arshad W, Shariq M: Mortality in diabetes mellitus - data from the developing regions of the world. Diabetes Res Clin Pract 1999, 43:6774.

5. Boykoe EJ, Lipsky BA: Infection and diabetes mellitus. Diabetes in America Washington DC: National Institutes of HealthHarris MI 1995, 485-496.

6. Sotto A, Bouziges N, Jourdan N, et al: In vitro activity of tigecycline against strains isolated from diabetic foot ulcers. Pathologie Biologie 2007, 55:398-406.

7. Muzaheed, Doi Y, Adams-Haduch JM, et al: Faecal carriage of CTX-M-15producing Klebsiella pneumoniae in patients with acute gastroenteritis. Indian J Med Res 2009, 129:599-602.

8. Cunha BA: Antibiotic selection for diabetic foot infections: a review. $J$ Foot Ankle Surg 2000, 39:253-257.

9. Wagner FW: The dysvascular foot: a system of diagnosis and treatment. Foot Ankle 1981, 2:64-122.

10. Cowan SF, Steel KJ: Manual for the Identification of the Medical Bacteria Cambridge: Cambridge University Press 1970.

11. Clinical and Laboratory Standards Institute: Performance Standards for Antimicrobial Susceptibility Testing: Eighteenth Informational Supplement. M100-S18. Wayne, PA 2008.

12. Jarlier V, Nicolas M, Fournier G, Philippon A: Extended spectrum $\beta$ lactamases conferring transferable resistance to newer $\beta$-lactam agents in Enterobacteriaceae: Hospital prevalence and susceptibility patterns. Rev Infect Dis 1988, 10:867-878.

13. Versalovic J, Koeuth T, Lupski JR: Distribution of repetitive DNA sequences in eubacteria and application to fingerprinting of bacterial genomes. Nucleic Acids Res 1991, 19:6823-6831.

14. Lee $\mathrm{H}$, Yong D, Yum JH, et al: Dissemination of $16 \mathrm{~S}$ rRNA methylasemediated highly amikacin-resistant isolates of Klebsiella pneumoniae and Acinetobacter baumannii in Korea. Diagn Microbiol Infect Dis 2006, 56:305312

15. Pagani L, Amico Dell E, Migliavacca R, et al: Multiple CTX-M-type extended-spectrum beta-lactamases in nosocomial isolates of Enterobacteriaceae from a hospital in northern Italy. J Clin Microbiol 2003, 41:4264-4269.

16. Doi Y, Yokoyama K, Yamane $\mathrm{K}$, et al: Plasmid mediated 16S rRNA methylase in Serratia marcescens conferring high level resistance to aminoglycosides. Antimicrob Agents Chemother 2004, 48:491-496.

17. Kado Cl, Liu ST: Rapid procedure for detection and isolation of large and small plasmids. J Bacteriol 1981, 145:1365-1373.

18. Guerra B, Soto S, Cal S, et al: Antimicrobial Resistance and Spread of Class 1 Integrons among Salmonella Serotypes. Antimicrob Agents Chemother 2000, 44:2166-2169.

19. Lederberg EM, Cohen SN: Transformation of Salmonella typhimurium by plasmid deoxyribonucleic acid. J Bacteriol 1974, 119:1072-1074

20. Gray KJ, Wilson LK, Phiri $A$, et al: Identification and characterization of ceftriaxone resistance and extended-spectrum $\beta$-lactamases in Malawian bacteraemic Enterobacteriaceae. J Antimicrob Chemother 2006, 57:661-665.

21. Arnold K, Bordoli L, Kopp J, et al: The SWISS-MODEL Workspace: A webbased environment for protein structure homology modelling. Bioinformatics 2006, 22:195-201.
22. Laskowski RA, Chistyakov W, Thornton JM: PDB sum more: new summaries and analyses of the known 3D structures of proteins and nucleic acids. Nucleic Acids Res 2005, 33:D266-268.

23. Eisenberg D, Luthy $R$, et al: VERIFY3D: assessment of protein models with three-dimensional profiles. Methods Enzymol 1997, 277:396-404.

24. Pellizzer G, Strazzabosco M, Presi S, Furlan F, Lora L, Benedetti P, et al: Deep tissue biopsy vs. superficial swab culture monitoring in the microbiological assessment of limb-threatening diabetic foot infection. Diabet Med 2001, 18:822-827.

25. Hartemann-Heurtier A, Robert J, Jacqueminet S, Ha Van G, Golmard JL, Jarlier $\mathrm{V}$, et al: Diabetic foot ulcer and multidrug-resistant organisms: risk factors and impact. Diabet Med 2004, 21:710-715.

26. Viswanathan $\mathrm{V}$, Jasmine JJ, Snehalatha C, Ramachandran A: Prevalence of pathogens in diabetic foot infection in South Indian type 2 diabetic patients. J Assoc Physicians India 2002, 50:1013-1016.

27. Lipsky BA, Berendt AR: Principles and practice of antibiotic therapy of diabetic foot infections. Diabetes Metab Res Rev 2000, 16:42-46.

28. Ikem RT, Kolawole BA, Ikem IC: The prevalence, presentation and outcome of diabetic foot lesions in a Nigerian teaching hospital. Trop Doct 2002, 32:226-227.

29. Prompers L, Schaper N, Apelqvist J: Prediction of outcome in individuals with diabetic foot ulcers: focus on the differences between individuals with and without peripheral arterial disease. The EURODIALE Study. Diabetologia 2008, 51:747-755.

30. Basit A, Hydrie MZ, Hakeem R, Ahmedani MY, Waseem M: Glycemic control, hypertension and chronic complications in type 2 diabetic subjects attending a tertiary care centre. J Ayub Med Coll Abbottabad 2005, 17:63-68

31. Minh HV, Byass $P$, Chuc NT, Wall S: Gender differences in prevalence and socioeconomic determinants of hypertension: findings from the WHO STEPs survey in a rural community of Vietnam. J Hum Hypertens 2006, 20:109-115.

32. Sader HS, Jones RN, Gales AC, et al: Antimicrobial susceptibility patterns for pathogens isolated from patients in Latin American medical centers with a diagnosis of pneumonia: analysis of results from SENTRY surveillance program (1997). Diagn Microbiol Infect Dis SENTRY Latin America Study Group 1998, 32:289-301.

33. Yu WL, Cheng KC: Emergence of Two Klebsiella pneumoniae Isolates Harboring Plasmid-Mediated CTX-M-15 $\beta$-Lactamase in Taiwan. Antimicrob Agents Chemother 2004, 48:362-363.

34. Touati A, Benallaoua S, Forte D, et al: First report of CTX-M-15 and CTX-M3 beta-lactamases among clinical isolates of Enterobacteriaceae in Béjaia, Algeria. Int J Antimicrob Agents 2006, 27:397-402.

35. Muzaheed, Doi Y, Adams-Haduch JM, Endimiani A, et al: High prevalence of CTX-M-15-producing Klebsiella pneumoniae among inpatients and outpatients with urinary tract infection in Southern India. J Antimicrob Chemother 2008, 61:1393-1394.

36. Ullah F, Malik SA, Ahmed J: Antimicrobial susceptibility and ESBL prevalence in Pseudomonas aeruginosa isolated from burn patients in the North West of Pakistan. Burns 2009, 35:1020-1025.

37. Rajini $E$, Sherwal $B L$, Anuradha : Detection of Extended-Spectrum $\beta$ lactamases in AmpC $\beta$-lactamase-Producing Nosocomial Gram-negative Clinical Isolates from a Tertiary Care Hospital in Delhi. Indian J Pract Doc 2008, 4, 2008-01-2008-02.

38. Khemtong S, Chuanchuen R: Class 1 integrons and Salmonella genomic island 1 among Salmonella enterica isolated from poultry and swine. Microb Drug Resist 2008, 14:65-70

39. Kim S, Hu J, Gautom R, et al: CTX-M extended-spectrum beta-lactamases, Washington State. Emerg Infect Dis 2007, 13:513-514.

40. Schmitt J, Jacobs E, Schmidt H: Molecular characterization of extendedspectrum beta-lactamases in Enterobacteriaceae from patients of two hospitals in Saxony, Germany. J Med Microbiol 2007, 56:241-249.

41. Lim KT, Yasin R, Yeo CC, Puthucheary S, Thong KL: Characterization of multidrug resistant ESBL-producing Escherichia coli isolates from hospitals in Malaysia. J Biomed Biotechnol 2009, 2009:165637.

42. Walsh TR: Clinically significant carbapenemases: an update. Curr Opin Infect Dis 2008, 21:367-371.

43. Zarrilli $R$, Vitale D, Di Popolo A, et al: A plasmid-borne blaOXA-58 gene confers imipenem resistance to Acinetobacter baumannii isolates from a Lebanese hospital. Antimicrob Agents Chemother 2008, 52:4115-4120. 
44. Bonnet R, Dutour C, Sampaio JL, et al: Novel cefotaximase (CTX-M-16) with increased catalytic efficiency due to substitution Asp-240Gly. Antimicrob Agents Chemother 2001, 45:2269-2275.

45. Schneider I, Queenan AM, Markovska R, et al: A new variant of CTX-M-type ESBLs, CTX-M-71, with a Gly238Cys substitution in a K. pneumoniae isolate from Bulgaria. Antimicrob Agents Chemother 2009, doi:10.1128/ AAC.00461-09.

46. Xiong Z, Zhu D, Wang F, et al: A Klebsiella pneumoniae producing three kinds of class A beta lactamases encoded by one single plasmid isolated from a patient in Huashan Hospital, Shanghai, China. Int J Antimicrob Agents 2004, 23:262-267.

47. Shakil S, Danishuddin M, Khan AU: Doripenem versus bacteria- an emerging battleground. J Chemother 2009, 21(5):482-92.

doi:10.1186/1476-0711-9-2

Cite this article as: Shakil and Khan: Infected foot ulcers in male and female diabetic patients: a clinico-bioinformative study. Annals of Clinical Microbiology and Antimicrobials 2010 9:2.

Publish with Biomed Central and every scientist can read your work free of charge

"BioMed Central will be the most significant development for disseminating the results of biomedical research in our lifetime. " Sir Paul Nurse, Cancer Research UK

Your research papers will be:

- available free of charge to the entire biomedical community

- peer reviewed and published immediately upon acceptance

- cited in PubMed and archived on PubMed Central

- yours - you keep the copyright 